\title{
Calibration values uninfluenced by the kind of pressure medium and the setting posture for quartz Bourdon-type pressure transducers
}

\author{
Hideaki lizumi ${ }^{1}$, Hiroaki Kajikawa ${ }^{1}$, Tokihiko Kobata ${ }^{1}$ \\ ${ }^{1}$ National Metrology Institute of Japan (NMIJ), AIST, 1-1-1 Umezono, Tsukuba, Ibaraki, 305-8563, Japan
}

\begin{abstract}
The effects of the kind of gas medium and the setting posture on the calibration values of a quartz Bourdon-type pressure transducer mounted vertically are evaluated in this study. The transducer, at the upward and downward settings, was calibrated both with nitrogen and with helium. The difference between the calibration values of the transducer with nitrogen at the upward and downward settings was about $7.0 \mathrm{kPa}$ at $100 \mathrm{MPa}$. At the same setting posture, the maximum difference in the calibration values between nitrogen and helium was $3.4 \mathrm{kPa}$. For precise pressure measurement, it is recommended that the transducers are used with the same pressure medium and the same setting posture with which they were calibrated. The methods of reducing the effects of both the kind of gas medium and the setting posture are discussed. The average of two calibration values at the upward setting and at the downward setting was not affected by the kind of gas medium. When the sensing elements of two pressure transducers arranged in point symmetry with each other, the average values of two transducers were independent of both the kind of gas medium and the setting posture.
\end{abstract}

\section{Section: RESEARCH PAPER}

Keywords: Pressure transducer; pressure medium; setting posture; high gas pressure

Citation: Hideaki lizumi, Hiroaki Kajikawa, Tokihiko Kobata, Calibration values uninfluenced by the kind of pressure medium and the setting posture for quartz Bourdon-type pressure transducers, Acta IMEKO, vol. 8, no. 3, article 5, September 2019, identifier: IMEKO-ACTA-08 (2019)-03-05

Editor: Rugkanawan Wongpithayadisai, NIMT, Thailand

Received August 31, 2018; In final form May 8, 2019; Published September 2019

Copyright: This is an open-access article distributed under the terms of the Creative Commons Attribution 3.0 License, which permits unrestricted use, distribution, and reproduction in any medium, provided the original author and source are credited.

Corresponding author: Hideaki lizumi, e-mail: h.iizumi@aist.go.jp

\section{INTRODUCTION}

High gas pressure is measured in various contexts, such as hydrogen stations, natural gas pipelines, industrial plants, and scientific research [1]-[4]. For ensuring reliable measurements, the National Metrology Institute of Japan (NMIJ), AIST has developed a high gas pressure standard for pressures up to 100 $\mathrm{MPa}$ using a liquid-lubricated pressure balance [5]-[7]. A quartz Bourdon-type pressure transducer [8]-[10] is one of the highest precision pressure gauges in the high gas pressure range. The accuracy of these pressure transducers is about $0.01 \%$ of the full scale. The characteristics of the pressure transducer have been evaluated in many institutes [11]-[14].

The quartz Bourdon-type pressure transducer is used as a transfer standard in some international comparisons of high gas pressure standards and hydraulic pressure standards [15]-[20]. In an international comparison of high gas pressure standards, we found that the calibration values of the quartz Bourdon-type pressure transducers are affected by the kind of gas medium used [15]. In this comparison, the transducers are previously calibrated both with nitrogen and with helium for the characterisation of the transducers, and the calibration values of the transducers depend on the kind of gas medium used. A recent article described the reason for these effects [21]. The indications of the transducers are affected by the weight of the pressure medium inside a sensing element. The calibration values of the horizontally mounted transducers also depend on the rotation angle around the central axis. It is found that the effects of the kind of gas medium can be reduced by adjusting the rotation angles of the transducers.

In this study, we investigate how to ensure that the calibration values are uninfluenced by the kind of gas medium and setting posture used. We evaluate the effect of the setting posture on the calibration values of transducers mounted horizontally [21]. In this paper, we evaluate the effects of both the kind of gas medium and setting posture used on the transducer mounted vertically. Using these evaluation results, the methods of reducing the effects of the kind of gas medium 

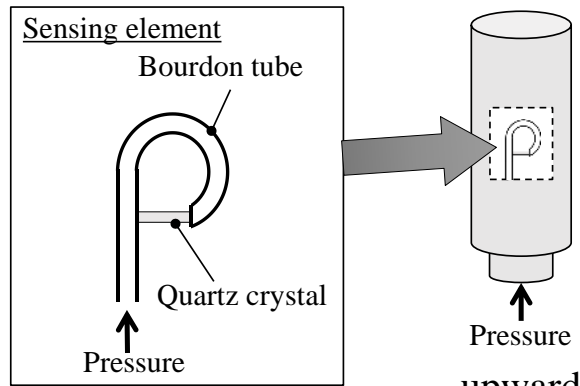

upward

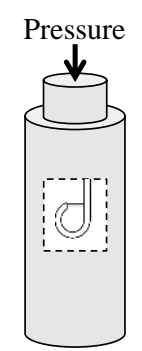

downward

Figure 1. Quartz Bourdon-type pressure transducer, set at upward and downward settings.

used are discussed. We also propose an appropriate arrangement for two transducers, with which the effects of both the kind of gas medium and the setting posture are highly reduced.

\section{REASON FOR THE EFFECTS OF THE KIND OF GAS MEDIUM AND SETTING POSTURE USED}

The sensing element of a quartz Bourdon-type pressure transducer [8]-[10] mainly consists of a Bourdon tube and a quartz crystal oscillator. In the sensing element, the quartz crystal oscillator is attached across the root and tip of the Bourdon tube, as shown in Figure 1. Pressure applied to the Bourdon tube generates an uncoiling force that applies tension to the quartz crystal. The change in the frequency of the quartz crystal oscillator as a function of the tension is a measure of the applied pressure.

The reason for the effects of the kind of gas medium used has been described in a recent article [21]. The indications are affected by the weight of the pressure medium inside the Bourdon tube. The weight of the pressure medium can cause the extensional or compressional deformation of the Bourdon tube, thereby affecting the oscillating frequency and, hence, the pressure indication. In this case, the indication of the transducer can be expressed as the sum of two contributions: the force acting on the Bourdon tube purely from the applied pressure and an extensional (or compressional) gravitational force arising from the weight of the pressure medium inside the Bourdon tube. Since the gas density largely varies depending on the kind of gas medium used [22], [23], the second term depends on both the kind of gas medium and the relationship between the directions of the gravitational force and the deformation of the Bourdon tube.

Therefore, it is thought that the indication of the pressure transducer, $I_{p}$, mounted vertically, is expressed by the following equation:

$I_{p}=I_{p}^{\prime} \pm \Delta I_{p}$.

Here, the first term $I_{p}^{\prime}$ represents the contribution purely from the applied pressure, and $\Delta I_{p}$ represents the effect of the weights of pressure medium inside the Bourdon tube. $\Delta I_{p}$ depends on both the kind of gas medium and the setting posture used. $\Delta I_{p}$ depends on the relationship between the directions of the gravitational force and the deformation of the Bourdon tube. When the transducer is set at the upward setting, as shown in Figure 1, the sign of $\Delta I_{p}$ is negative because the gravitational force arising from the weight of the pressure

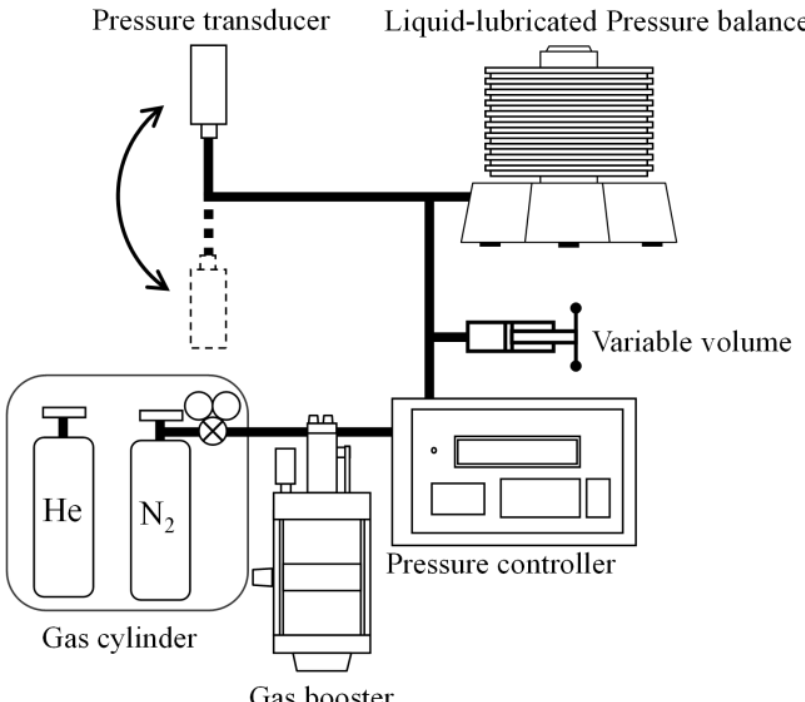

Figure 2. Schematic drawing of a high gas pressure calibration system.

medium causes the compressional deformation of the Bourdon tube. Conversely, when the transducer is set at the downward setting, $\Delta I_{p}$ is positive because the gravitational force causes extensional deformation.

In the next section, the above assumption was experimentally confirmed by calibrating the vertically mounted pressure transducer, both with nitrogen and with helium.

\section{THE EFFECTS AT VERTICAL SETTINGS}

\subsection{Calibration methods}

Figure 2 shows a schematic drawing of a high-gas pressure calibration system in NMIJ [5]. A pressure supply source is gas cylinder. A gas booster with a maximum compression ratio of 25:1 pressurises the gas to about $100 \mathrm{MPa}$. Pressurised gas is supplied to the pressure controller, which is used to accurately adjust the gas pressure and supply a sufficiently stable pressure to a liquid-lubricated pressure balance and the pressure transducer. A variable volume is also used to manually adjust the piston's floating position. The liquid-lubricated gas pressure balance is used as a standard device.

The calibration is conducted by comparing the applied pressure from the liquid-lubricated pressure balance with the indication of the pressure transducer. The target pressure was changed from $0 \mathrm{MPa}$ to $100 \mathrm{MPa}$ in steps of $10 \mathrm{MPa}$. At each target pressure, the indication of the pressure transducer was sampled 18 times at $10 \mathrm{~s}$ intervals, after waiting 7 mins following the establishment of a steady pressure. The difference between the pressure applied by the standard and the indication of the pressure transducer after offset correction at nominal gauge pressure $p \mathrm{MPa}, R_{p}$, is calculated as

$\mathrm{R}_{p}=\left(I_{p}-S_{p}\right)-\left(\mathrm{I}_{\partial}-S_{0}\right)$.

Here, $S_{p}$ is the pressure applied by the standard. The mean value of $R_{p}$ in three ascending processes is used as the calibration value.

The quartz Bourdon-type pressure transducer (Paroscientific Inc., Model 9000-15K, pressure range $100 \mathrm{MPa}$ ) [8] was calibrated at the upward and downward settings as shown in Figure 1. The reference level for each pressure transducer was determined as the level at the end face of the inlet port. Nitrogen and helium were used as the pressure media. 


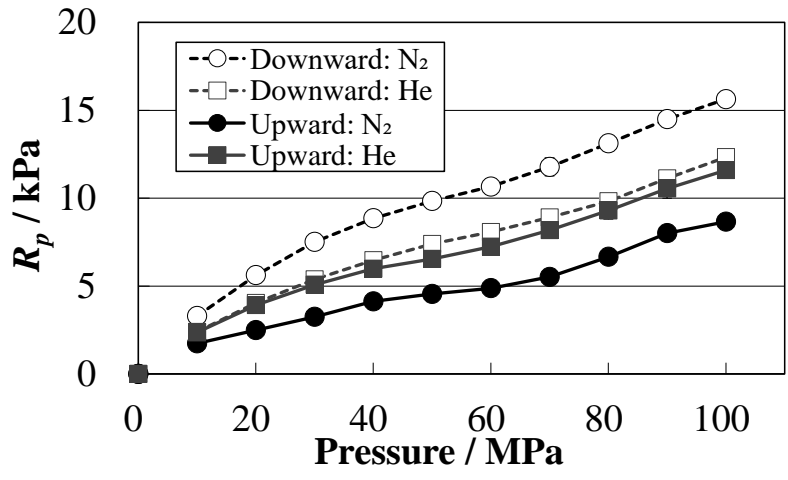

Figure 3. Calibration results $R_{p}$ at the upward and downward settings, both with nitrogen and with helium.

\subsection{Calibration results}

The calibration results of the pressure transducers at the upward and downward settings are shown in Figure 3. $R_{p}$ depends on both the pressure medium and the setting posture. The standard deviation of $R_{p}$ in the three ascending processes was less than $0.6 \mathrm{kPa}$ in all measurement pressure. The difference between $R_{p}$ at the upward and downward settings was larger than the standard deviations. The same difference with nitrogen at $100 \mathrm{MPa}$ was about $7.0 \mathrm{kPa}$, relatively $7.0 \times 10^{-5}$ of the full scale. When the transducer is set at the downward setting, the gravitational force arising from the weight of the pressure medium causes the extensional deformation of the Bourdon tube, and when the transducer is set at the upward setting, the gravitational force causes compressional deformation. Therefore, $R_{p}$ at the downward setting was larger than $R_{p}$ at the upward setting. The effects of the setting posture with helium were smaller than that with nitrogen because the density of helium is smaller than that of nitrogen. At the same setting posture, the maximum difference between $R_{p}$ with nitrogen and $R_{p}$ with helium was $3.4 \mathrm{kPa}$, relatively $3.4 \times 10^{-5}$ of the full scale.

\section{METHODS FOR REDUCING THE EFFECTS}

\subsection{Using a single pressure transducer}

Since the quartz Bourdon-type pressure transducer was affected by the kind of gas medium and the setting posture, it is recommended that the transducers are used with the same

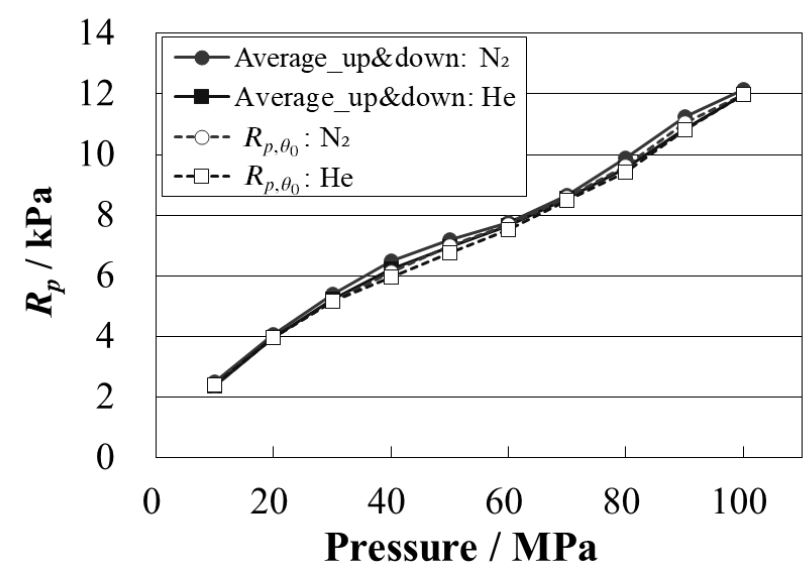

Figure 5. Average values of calibration values at the upward and downward settings. Calibration values at horizontal settings with rotation angle $\theta_{0}$.

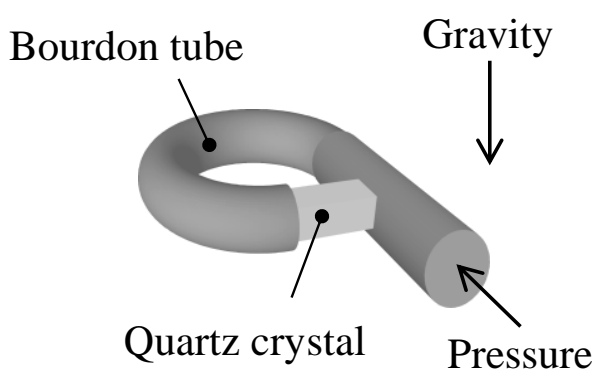

Figure 4. Setting posture of sensing element, $\theta_{0}$. Direction of deformation of Bourdon tube is perpendicular to direction of gravitational force.

pressure medium and the same setting posture with which they were calibrated.

The two methods for reducing the effect of the kind of gas medium are discussed. When the transducer is mounted vertically, the deformation of the Bourdon tube by the gravitational force arising from the weight of the pressure medium at the upward setting is opposite to that at the downward setting. Therefore, it is thought that the effect of the weight of the pressure medium can be eliminated by averaging the calibration values at the upward and downward settings.

When the transducer is mounted horizontally, there is a particular rotation angle, $\theta_{0}$, where there is no effect of the gas medium. The method of identifying the rotation angle $\theta_{0}$ by the experiment has been reported in other studies [21]. At the rotation angle $\theta_{0}$, the direction of the deformation of the Bourdon tube is perpendicular to the direction of gravitational force, as shown in Figure 4.

Figure 5 shows the average value of $R_{p}$ at the upward and downward settings both with nitrogen and with helium. The calibration values of the horizontally mounted transducer at the rotation angle $\theta_{0}, R_{p, \theta_{0}}$, both with nitrogen and with helium are also shown. Each value showed good agreement within $0.6 \mathrm{kPa}$ in all measurement pressures. $0.6 \mathrm{kPa}$ was comparable to the standard deviations of the calibration value. The average value of the $R_{p}$ at the upward and downward settings agreed well with $R_{p, \theta_{0}}$ because both values only included the contribution purely from the applied pressure. The effect of the kind of gas medium on the calibration value can be reduced by averaging the calibration values at the upward and downward settings or by adjusting the setting posture of the transducers.

\subsection{Using two pressure transducers}

In the international comparison, two pressure transducers are used as the transfer standard for securing redundancy. We discuss here the case in which two transducers can be used for measurements. It is thought that the effect of the kind of gas medium used can also be reduced by averaging the calibration values of two transducers at the upward setting and at the downward setting. In addition, when the sensing elements of the two pressure transducers are arranged in point symmetry with each other, the deformations of the two Bourdon tubes by the gravitational force arising from the weight of the pressure medium are opposite to each other in any setting posture. Therefore, it is thought that the effects of both the kind of gas medium and the setting posture used can also be reduced by averaging the calibration values of the two arranged transducers.

Figure 6 shows a point-symmetry arrangement of two transducers. The inlet port of two transducers A and B at 


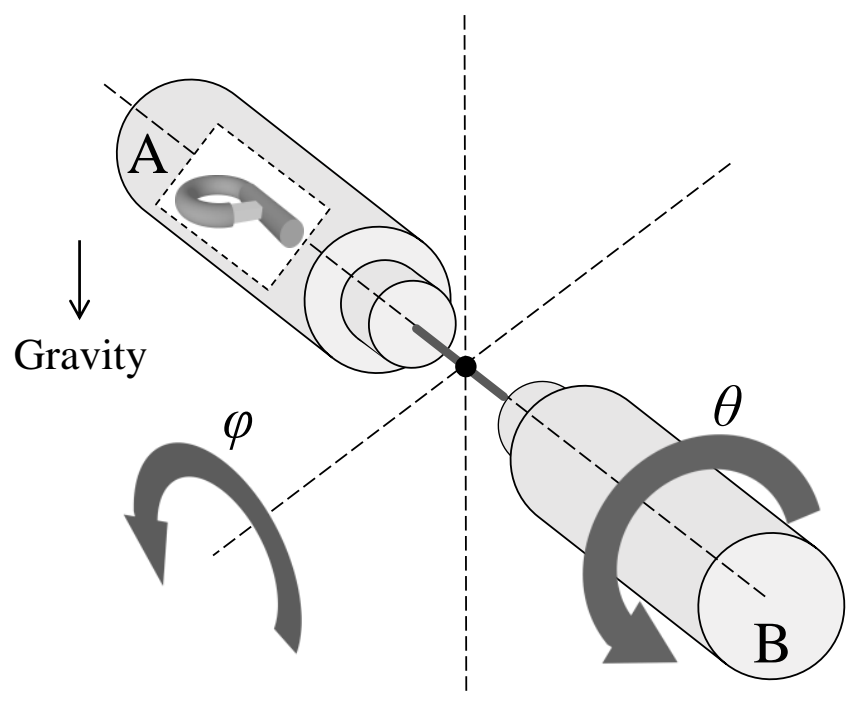

Figure 6. Two pressure transducers at rotation angle $\theta_{0}$ are positioned in point symmetry with each other. This posture is defined as $\theta=90^{\circ}, \varphi=90^{\circ}$.

rotation angle $\theta_{0}$ were arranged face to face with each other. This posture was defined as $\theta=90^{\circ}, \varphi=90^{\circ}$.

The set of two transducers arranged in point symmetry were mounted vertically $\left(\varphi=0^{\circ}\right.$ and $\left.180^{\circ}\right)$, and both were calibrated with nitrogen and with helium. The rotation angle $\theta$ was fixed to $90^{\circ}$. When $\varphi=0^{\circ}$, transducer $\mathrm{A}$ was set at the upward setting and transducer $\mathrm{B}$ was set at the downward setting. When $\varphi=180^{\circ}$, transducer A was set at the downward setting, and transducer $B$ was set at the upward setting. The $R_{p}$ of the two transducers were averaged. Figure 7 shows the average value of the two transducers, $R_{p, \text { ave }}$, both with nitrogen and with helium at $\varphi=0^{\circ}$ and $180^{\circ}$. At the same setting posture, $R_{p, \text { ave }}$ with nitrogen and $R_{p, \text { ave }}$ with helium showed good agreement within $0.7 \mathrm{kPa}$ in all measurement pressures, relatively $7.0 \times 10^{-6}$ of the full scale. $0.7 \mathrm{kPa}$ was comparable to the standard deviations of the calibration value. In addition, $R_{p, a v e}$ at $\varphi=0^{\circ}$ and $180^{\circ}$ showed good agreement.

Two transducers A and B, arranged as shown in Figure 7, were calibrated at different setting postures. The pressure medium was nitrogen. In the first experiment, the rotation angle $\varphi$ was fixed to $90^{\circ}$. The rotation angle $\theta$ was changed in order of $90^{\circ}, 45^{\circ}, 0^{\circ}, 90^{\circ}, 135^{\circ}, 180^{\circ}, 90^{\circ}$. Figure 8 (a) shows the calibration values at $100 \mathrm{MPa}, R_{100}$, of transducer $\mathrm{A}$ and $\mathrm{B}$ at each rotation angle $\theta$. The average values of the two transducers are also shown. The three $R_{100}$ at $\theta=90^{\circ}$ showed good agreement within $0.5 \mathrm{kPa}$ in both transducers $\mathrm{A}$ and $\mathrm{B}$. Although the maximum difference by the rotation angle $\theta$ of transducer $\mathrm{A}$ was $7.2 \mathrm{kPa}$ and transducer $\mathrm{B}$ was $7.0 \mathrm{kPa}$, the average values were $0.5 \mathrm{kPa}$. The average values were not affected by the rotation angle $\theta$.

In the second experiment, the rotation angle $\theta$ was fixed to $90^{\circ}$. The rotation angle $\varphi$ was changed in order of $90^{\circ}, 45^{\circ}, 0^{\circ}$, $90^{\circ}, 135^{\circ}, 180^{\circ}, 90^{\circ}$. Figure $8(\mathrm{~b})$ shows the $R_{100}$ of transducers $A$ and $B$ at each rotation angle $\varphi$. The average values of the two transducers are also shown. The three $R_{100}$ at $\varphi=90^{\circ}$ showed good agreement within $0.5 \mathrm{kPa}$ in both transducers $\mathrm{A}$ and $\mathrm{B}$. Although the maximum difference of rotation angle $\varphi$ of transducer $\mathrm{A}$ was $7.8 \mathrm{kPa}$ and transducer $\mathrm{B}$ was $9.5 \mathrm{kPa}$, the average value was $1.0 \mathrm{kPa}$. In both cases, the effect of the setting posture on the calibration value can be reduced by averaging the calibration values of the two transducers.

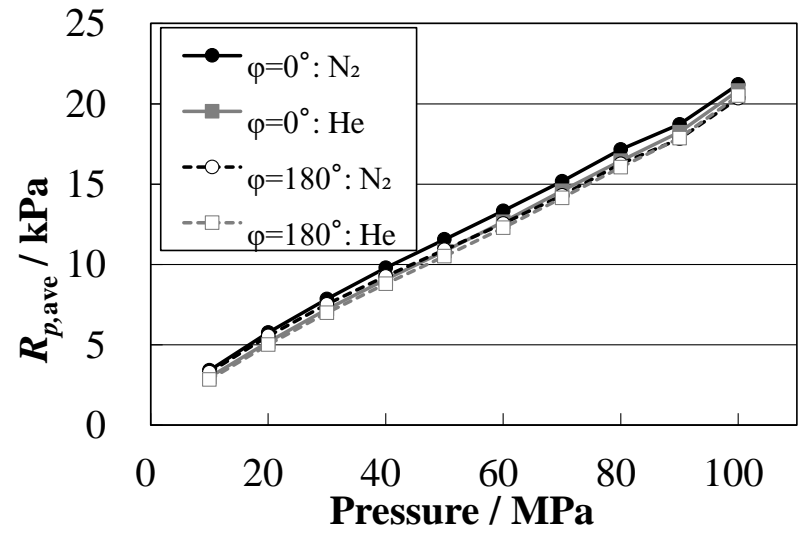

Figure 7. Average value of two transducers, $R_{p, \text { ave, }}$ at $\varphi=0^{\circ}$ and $180^{\circ}$ both with nitrogen and with helium.

When the sensing elements of the two pressure transducers were arranged in point symmetry, their average values were almost independent of both the kind of gas medium and the setting posture used. If two transducers that have the same effects are used, the average values would be completely independent of both the kind of gas medium and the setting posture used. In this study, the inlet ports of the two transducers were arranged face to face with each other. However, the same results can be obtained as long as the sensing elements are arranged in point symmetry with each other.

\section{CONCLUSIONS}

A quartz Bourdon-type pressure transducer is one of the highest precision pressure gauges in a high gas pressure range. This study found that the calibration values of the quartz Bourdon-type pressure transducers are affected by the kind of
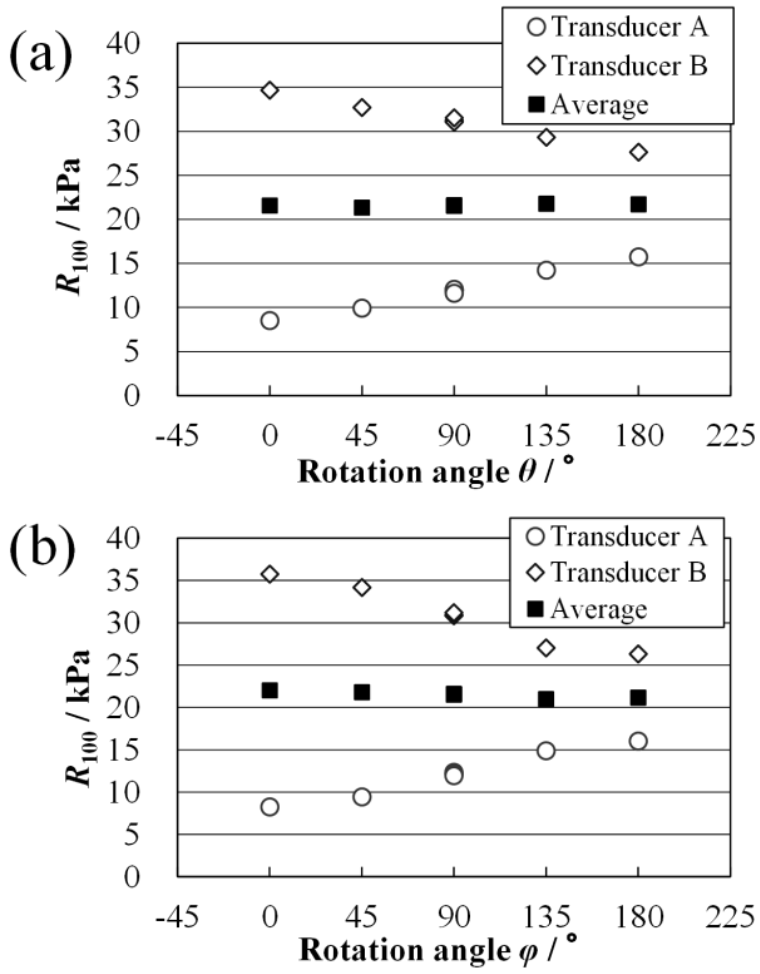

Figure 8 . Calibration values at $100 \mathrm{MPa}, R_{100}$, of transducers $\mathrm{A}$ and $\mathrm{B}(\mathrm{a})$ at different rotation angles $\theta$; (b) at different rotation angles $\varphi$. The average values of the two transducers are also shown. 
gas medium used. This is because the indications of the transducers are affected by the weight of the pressure medium inside a sensing element. The weight of the pressure medium can cause extensional or compressional deformation of the Bourdon tube in the sensing elements, affecting the oscillating frequency and, hence, the pressure indications. The indications depend on both the kind of gas medium and the setting posture used. In this study, the effects of the kind of gas medium and the setting posture on the vertically mounted transducer were evaluated. The transducer at the upward and downward settings was calibrated both with nitrogen and with helium. The difference between the calibration values of the transducer at the upward and downward settings was about $7.0 \mathrm{kPa}$, relatively $7.0 \times 10^{-5}$ of full scale. At the same setting posture, the maximum difference in the calibration values between nitrogen and helium was $3.4 \mathrm{kPa}$, relatively $3.4 \times 10^{-5}$ of the full scale. For precise pressure measurement, it is recommended that the transducers are used with the same pressure medium and the same setting posture with which they were calibrated.

The methods of reducing the effects of the kind of gas medium used have been discussed. Since the deformation of the Bourdon tube due to the gravitational force arising from the weight of the pressure medium at the upward setting is opposite to that at the downward setting, it was found that the effect of the kind of gas medium used can be reduced by averaging the calibration values at the upward and downward settings. The average value of the calibration values at the upward and downward settings with nitrogen agreed well with the average value with helium.

In addition, the effects of the kind of gas medium used were reduced by averaging the calibration values of two transducers at the upward setting and at the downward setting. When the sensing elements of the two pressure transducers are arranged in point symmetry with each other, the deformations of the two Bourdon tubes by the gravitational force arising from the weight of the pressure medium are opposite to each other in any setting posture. Therefore, it was thought that the effect of both the kind of gas medium and the setting posture used can also be reduced by averaging the calibration values of the two arranged transducers. The two arranged transducers were calibrated at different settings with nitrogen. The maximum difference in the transducer's calibration values due to the setting posture was $9.5 \mathrm{kPa}$. However, the maximum difference of the average values of the two arranged transducers was $1.0 \mathrm{kPa}$. When the sensing elements of the two pressure transducers were arranged in point symmetry, the average values of the two transducers were independent of both the kind of gas medium and the setting posture used.

\section{REFERENCES}

[1] UN/ECE, Global technical regulation No. 13: Global technical regulation on hydrogen and fuel cell vehicles, 2013.

[2] NIST Handbook 44, 2013 Edition: Specifications, tolerances, and other technical requirements for weighing and measuring devices. Section 3.39: Hydrogen gas-measuring devices tentative code.

[3] EMRP Call 2013 - Energy and environment: SRT-g05 Metrology for hydrogen transport, 2013. Online [Accessed 20190920] http://www.emrponline.eu/call2013/SRTs/SRT-g05.pdf.

[4] N. Sakoda, K. Onoue, T. Kuroki, K. Shinzato, M. Kohno, M. Monde, Y. Takata, Transient temperature and pressure behavior of high-pressure $100 \mathrm{MPa}$ hydrogen during discharge through orifices, International Journal of Hydrogen Energy 41 (2016) pp. 17169-17174.
[5] H. Iizumi, H. Kajikawa, T. Kobata, A high gas pressure calibration system using a liquid-lubricated pressure balance, Measurement 102 (2017) pp. 106-111.

[6] T. Kobata, Improved methods for comparing gas and hydraulic pressure balances, Metrologia 46, 5 (2009) pp. 591-598.

[7] P. Delajoud, M. Girard, 'A new piston gauge to improve the definition of high gas pressure and to facilitate the gas to oil transition in a pressure calibration chain', Proc. of the International Symposium on Pressure and Vacuum (IMEKO TC16), Beijing, China, 21 - 24 September 2003, pp.154-159.

[8] Paroscientific Inc., 2013: User's Manual for Digiquartz Broadband Intelligent Instruments with Dual RS-232 and RS-485 Interfaces.

[9] Paroscientific Inc. 2009: User's Manual for Model 735 Intelligent Display and Model 745 High Accuracy Laboratory Standard.

[10] Fluke Calibration 2012: RPM4 Operation and Maintenance Manual.

[11] T. Kobata, Characterization of quartz Bourdon-type highpressure transducers, Metrologia 42 (2005) S235.

[12] H. Kajikawa, T. Kobata, Effects of pressurization procedures on calibration results for precise pressure transducers, Meas. Sci. Technol. 21 (2010) 065104.

[13] I. Kocas, M. Bergoglio, An investigation of quartz type pressure transducer behavior under continuous pressure conditions and metrological characterization, Measurement 45 (2012) pp. 24862489.

[14] W.W. Chadwick Jr., S.L. Nooner, M.A. Zumberge, R.W. Embley and C.G. Fox, Vertical deformation monitoring at Axial Seamount since its 1998 eruption using deep-sea pressure sensors, Journal of Volcanology and Geothermal Research 150 (2006) pp. 313-327.

[15] H. Kajikawa, D.A. Olson, H. Iizumi, R.G. Driver, M. Kojima, Final report on supplementary comparison APMP.M.P-S6 in gas gauge pressure from $10 \mathrm{MPa}$ to $100 \mathrm{MPa}$, Metrologia 53-TS (2016) 03002.

[16] T. Kobata, A. K. Bandyopadhyay, K. Moore, A. A. E. Eltawil, S. Y. Woo, T. K. Chan, W. Jian, J. Man, N. N. Con, C. S. Fatt, W. Permana, M. Aldammad, W. Sabuga, T. Changpan, C. C. Hung, Z. Pengcheng, Final report on key comparison APMP.M.P-K7 in hydraulic gauge pressure from $10 \mathrm{MPa}$ to $100 \mathrm{MPa}$, Metrologia 42-TS (2005) 07006.

[17] T. Kobata, H. Kajikawa, S. Kimura, M. Fitzgerald, D. Jack, C. Sutton, W. A. M. W. Mohamed, M. M. Mansor, C. S. Fatt, Final report on key comparison APMP.M.P-K7.1 in hydraulic gauge pressure from $10 \mathrm{MPa}$ to $100 \mathrm{MPa}$, Metrologia 46-TS (2009) 07008.

[18] J. C. G. Romero, M. C. Neira, J. C. Torres-Guzman, Final report of supplementary comparison SIM.M.P-S7: Hydraulic pressure comparison from $7 \mathrm{MPa}$ to $70 \mathrm{MPa}$, Metrologia 50-TS (2013) 07014.

[19] J. C. Torres-Guzman, 'Pressure standards comparison between Germany and Mexico', Proc. of the 2002 NCSL International Workshop and Symposium, San Diego, USA, 4-8 August 2002.

[20] EURAMET Project No 1252: Comparison in the range of 10 $\mathrm{MPa}$ to $100 \mathrm{MPa}$ of liquid pressure. Online [Accessed 20190920]: https://www.euramet.org/technical-committees/search-tcprojects/details/?eurametCtcp project show $\% 5$ Bproject $\% 5 \mathrm{D}=$ 1026\&eurametCtcp project $\% 5$ Bback $\% 5 \mathrm{D}=188 \& \mathrm{cHash}=\mathrm{af} 8693$ 5f61350bdaacb958e4a0a05289

[21] H. Iizumi, H. Kajikawa, T. Kobata, Effect of the kind of gas medium on calibration values of high gas pressure transducers, Measurement, 131 (2019) pp. 358-361.

[22] R. Span, E. W. Lemmon, R. T. Jacobsen, W. Wagner, A. Yokozeki, A reference equation of state for the thermodynamic properties of nitrogen for temperatures from 63.151 to $1000 \mathrm{~K}$ and pressures to $2200 \mathrm{MPa}$, J. Phys. Chem. Ref. Data 29-6 (2000) pp.1361-1433.

[23] R. D. McCarty, V. D. Arp, A new wide range equation of state for helium, Adv. Cryog. Eng. 35 (1990) pp. 1465-1475. 